\title{
Parent-Reported Diabetic-Specific Health Related Quality of Life in Children Treated with Multiple Daily Injection, Continuous Subcutaneous Insulin Infusion and Flexible Multiple Daily Injection: A Comparative Study
}

\author{
Anutosh Shee ${ }^{1,2}$, Sarah Prior ${ }^{1}$, Nicole Reeves ${ }^{1}$, Maria Smith $^{2}$, Sharon Luccisano ${ }^{2}$ \\ ${ }^{1}$ Rural Clinical School, School of Medicine, University of Tasmania, Tasmania, Australia \\ ${ }^{2}$ Tasmanian Health Service - North West, Tasmania, Australia
}

\section{Email address:}

anutosh.shee@ths.tas.gov.au (A. Shee), sarah.prior@utas.edu.au(S. Prior), nicole.reeves@utas.edu.au(N. Reeves), maria.smith@ths.tas.gov.au (M. Smith),sharon.luccisano@ths.yas.gov.au (S.Luccisano)

\section{To cite this article: \\ Anutosh Shee, Sarah Prior, Nicole Reeves, Maria Smith, Sharon Luccisano. Parent-Reported Diabetic-Specific Health Related Quality of Life in Children Treated with Multiple Daily Injection, Continuous Subcutaneous Insulin Infusion and Flexible Multiple Daily Injection: A Comparative Study. International Journal of Diabetes and Endocrinology. Vol. 4, No. 1, 2019, pp. 6-12. doi: 10.11648/j.ijde.20190401.12}

Received: December 16, 2018; Accepted: January 5, 2019; Published: January 29, 2019

\begin{abstract}
Aims: This study aims to identify differences in diabetes specific health related quality of life (HRQoL) in children and adolescents with type 1 diabetes mellitus (T1D) treated with three distinct types of intensive insulin therapymultiple daily injection (MDI), continuous subcutaneous insulin infusion (CSII) and flexible multiple daily injection (fMDI). Materials and Methods: This survey was conducted in north west Tasmania over a 6-month period, during quarterly clinic visits. A well-known, reliable and validated survey tool -Paediatric Quality of life (PedsQL) Diabetes Module 3.0 was used to capture information about the diabetic specific HRQoL in children and adolescents. The parent-proxy version of the forms was completed by the parents electronically using iSurvey application to secure information regarding their children's diabetes related symptoms (11 items), treatment barriers ( 4 items), treatment adherence ( 7 items), worry ( 3 items) and communication ( 3 items). All de-identified information was downloaded into an excel spreadsheet and SPSS V24.0 for further analysis. Results: 34 parents completed the electronic data forms on iSurvey. There were no statistically significant differences in HRQoL among the CSII, MDI and fMDI groups as determined by one-way ANOVA in diabetes $\{F(2,31)=0.517, p=0.601\}$, treatment $\{F(2,31)=0.385, p=0.684\}$, worry $\{F(2,31)=0.076, p=0.927\}$, and communication $\{F(2,31)=0.672, p=$ 0.518 \}. Conclusion: Although, the impact of T1D on the HRQoL in children and adolescents is higher than the children without T1D, it appears to be independent of the types of three intensive insulin therapy generally used- CSII, MDI and fMDI, suggesting type of insulin therapy may not be the major influencing factor for children' quality of life as revealed in this first of its kind study. A further study with higher number of participants and the additional impact of various glucose monitoring systems on the HRQoL is highly recommended, which may influence the decision of right therapy suitable for the entire family.
\end{abstract}

Keywords: Type 1 Diabetes Mellitus, Continuous Subcutaneous Insulin Infusion, Flexible Multiple Daily Injection, Multiple Daily Injection, Health Related Quality of Life,

Paediatric Quality of life (PedsQL) Diabetes Module 3.0

\section{Introduction}

Type 1 diabetes mellitus (T1D): type 1 diabetes mellitus, CSII: Continuous Subcutaneous Insulin Infusion, HbAlc: Glycosylated haemoglobin, MDI: Multiple Daily Injection,
fMDI: Flexible Multiple Daily Injection, SH: Severe Hypoglycaemia, DKA: Diabetic Ketoacidosis, CGM: Continuous Glucose Monitoring, HRQoL: Health Related Quality of Life, D-HRQoL: Diabetes Specific Health Related Quality of Life, AP: Artificial Pancreatic System. 
Type 1 diabetes mellitus (T1D) is one of the most common chronic medical conditions in children and young adults equally affecting males and females with a significant impact on the health-related quality of life (HRQoL) particularly in adolescents. [1] Although, it affects nearly half a million people worldwide, fortunately, the overall incidence has not risen over the last 15 years in Australia. [2] The impact on HRQoL seems to be less in T1D than some of the other chronic common paediatric problems such as ADHD, as shown in a recent study in Scotland. [3] HRQoL in children with T1D is influenced by multiple clinical and sociodemographic factors including age, gender, duration of diabetes, needle phobia, fear of hypoglycaemia, associated comorbidities and complications, mode of insulin administration and associated glucose measurement systems such as finger pricking, flash glucometer and continuous glucose monitoring (CGM) and finally cognitive and affective resources of the entire family. The availability of technologies such as flash glucometer, CGMs, devices with reduced needs for injection prick (e.g. i-port advance), sensor augmented insulin pump, artificial pancreatic system and different types of insulin analogues usage are all continuously changing the way T1D is treated and therefore, its impact on the HRQoL. It is also to be remembered that emerging technologies can often be counterproductive due to digital information overload.

Intensive insulin therapy is the gold standard for the management of T1D, replacing the twice daily (BD) insulin dosing following the outcome report of the landmark Diabetes Control and Complication Trial, conducted over a period of three decades. [4] Three different types of intensive therapy are currently practiced worldwide- continuous subcutaneous insulin infusion (CSII) delivered by pump and multiple daily injection -either by fixed dose (MDI) or by flexible dose (fMDI) depending on the meal-time carbohydrate intake. Over time, insulin treatment regimens have changed worldwide with the primary aim to improve glycaemic control. However, treatment satisfaction and HRQoL are equally important before selecting the right type of insulin therapy suitable for the entire family. There are number of studies showing the glycaemic control in two types of insulin therapy, comparing the CSII and MDI, the largest being the analysis of SWEET (Better control in Paediatric and Adolescent diabeteS: Working to crEate CEnTers of Reference) registry which included 16,570 children with T1D showing that both HbA1c and daily insulin dose $(\mathrm{U} / \mathrm{kg} / \mathrm{d})$ remained decreased in children treated with CSII compared to MDI $(\mathrm{P}<.0001)$ both in pre-schooler and school aged children. [5] Another meta-analysis consisting of seven RCTs involving a total of 220 children with T1D demonstrated that CSII was associated with statistically significant, marginal decrease in HbAlc level ( $\mathrm{MD}=-0.24 \%, 95 \% \mathrm{CI}=-0.41$ to -0.07 ) without significant differences in episodes of severe hypoglycaemia ( $\mathrm{SH}$ ) and diabetic ketoacidosis (DKA) than MDI [6].

Fixed dose MDI is administered as a combination of long acting basal insulin injection and a fixed amount of meal- time boluses, ideally given 15 minutes before the meal. CSII offers added advantage over fixed dose MDI, requiring less number of injections (usually takes 3 days of needle change) but most importantly, can give variable basal rate depending on the time of the day, which is more physiological. This can also offer meal-time flexibility, easier management during the sports days and can administer a correction dose without pricking any extra injection. This is often considered as a life-style choice. However, not everyone with T1D wishes to use CSII. An alternative way of intensive insulin treatment was developed using flexible multiple daily injection (fMDI), which is gaining popularity. The concept of fMDI offers better meal-time flexibility in dietary selection yet having good glycaemic control. For both CSII and fMDI to be effective carbohydrate counting is essential. A study in UK suggested that the training promoting dietary freedom involving carbohydrate counting has been very effective and it improved the HRQoL and glycaemic control in people with T1D without worsening severe hypoglycaemia or cardiovascular risk. [7] In another study in 2002, at the Children's Hospital of Wisconsin Diabetes Center, USA, a significant improvement in $\mathrm{HbAlc}$ in prepubertal $(9.3 \% \pm 1.3 \%$ vs. $8.0 \% \pm 1.1 \%, \quad p<0.002)$ and pubertal subjects $(9.2 \% \pm 1.0 \%$ vs. $8.2 \% \pm 0.9 \%, p<0.001)$ with fMDI compared to the conventional therapy was demonstrated. Most importantly, the rate of severe hypoglycaemia decreased in both prepubertal $(p<0.01)$ and pubertal $(p<0.05)$ groups. [8] No study, to our knowledge, has previously compared the glycaemic control and HRQoL in all three types of intensive insulin therapy namely MDI, fMDI and CSII.

Generally, children with T1D report similar HRQoL as the rest of the population of the same age with slightly worse physical well-being even among those aged 11-17 years with early-onset T1D. [9, 10] However, a study from Greece had suggested that HRQoL in T1D is worse than the general population. In addition, HRQoL has been noticed to be perceived differently, parents of children and adolescents with T1D reported that the illness had a greater effect on their children's lives than the children perceived themselves. Later age of onset of diabetes, less hyperglycaemic episodes, lower $\mathrm{HbAlc}$, older age, and male gender were associated with better general HRQoL and diabetes-specific HRQoL. [1, 11] In our study we aimed to understand the impact of various types of intensive insulin therapy - CSII, MDI and fMDI on HRQoL in children with T1D. To our knowledge this is first of its kind comparing all three types.

\section{Materials and Methods}

\subsection{Participants}

A total of 35 parents of children with T1D were enrolled for the study during their quarterly multidisciplinary diabetic clinic visits. Children were utilising one of three types of insulin regimen- $\mathrm{MMDI}$, MDI and CSII. 


\subsection{Procedure}

This survey-based study was conducted with the approval of and in accordance with the policies and procedures of the University of Tasmania Health and Medical Human Research Ethics Committee. After obtaining informed consent, parents were administered a self-report questionnaire containing demography questions and Paediatric Quality of Life (PedsQL) Diabetes Module 3.0 on an electronic tablet. The data was collected electronically via iSurvey and then deidentified information was downloaded into an 'Excel spreadsheet' and SPSS V24.0 for further analysis.

Paediatric Quality of life (PedsQL) Diabetes Module 3.0 ((Information Resources Centre, Mapi Research Trust, France) is a reliable and validated tool (both parent proxyreport and children completed) which assesses diabetes specific health-related quality of life in children and adolescents. (12) The measure contains separate questionnaires relevant to 4 age groups: 2-4 years, 5-7 years, 8-12 years and 13-18 years. Each questionnaire contains 28 items within five domains: diabetes symptoms (11 items); treatment barriers (4 items); treatment adherence (7 items); worry (3 items); and communication (3 items). The questionnaire measures items on a 5-point Likert scale where the higher score indicates a problem with the domain being questioned $(0=$ never a problem to $4=$ almost always a problem. Items are then reverse-scored and linearly transformed into a Likert scale with a $0-100$ range $(0=100$, $1=75,2=50,3=25,4=0)$, so that higher scores indicate better HRQoL. [12] The summary of the study design is explained in the figure 1.

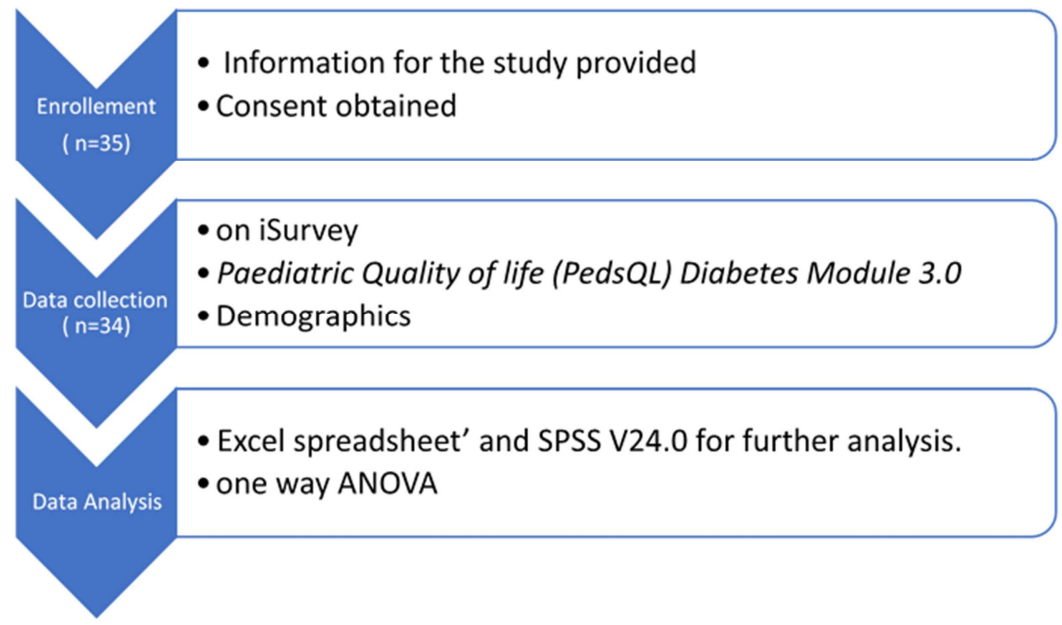

Figure 1. The process of the study.

\section{Results}

\subsection{Demographics}

A total of 35 parents of children $(M$ age $=13.4$ years, $S D=$ 3.87 years, Range 3-18 years, 51\% female) were enrolled for the study. The length of time since diagnosis of T1D ranged from $0-15$ years $(M=5.52$ years, $S D=4.78$ years $)$. One parent withdrew before administering the questionnaire due to time constraint. Twenty parents $(59 \%)$ were aged between $30-49$ years. Two parents $(0.6 \%)$ were of aboriginal Australian descent. Most of the parents were employed (74\%), either in a fulltime or casual position. Nearly onethird $(32 \%)$ of all respondents were either advanced diploma holders or above. Fifty percent of the parents were married. Table 1 shows the demographics for the parental group.

Our study group also indicated only $10 \%$ of the children with T1D were below 8 years old. Overall, there were equal number of males and females affected. More than threequarters of all children had acceptable BMI, with $5 \%$ being obese. Most of the children in our study group were using MDI (14/35), followed by CSII (11/35) and fMDI (10/35). Fourteen children (40\%) had previously switched from MDI to a different type of insulin regimen (fMDI or CSII). [Figure
2] Insulin glargine and insulin aspart/lispro delivered by pen were used as a long-acting and meal-time insulin agent, respectively for both fMDI and MDI regimen. Only, insulin aspart was used for all the children with CSII in our cohort. Table 2 shows the demographic information for the patient (children) group.

Table 1. Demographic information of parents of children with type 1 diabetes.

\begin{tabular}{ll}
\hline Variables & $\boldsymbol{n}=\mathbf{3 4}$ \\
\hline Age & 5 \\
$18-29$ & 20 \\
$30-49$ & 8 \\
$50-64$ & 1 \\
$65+$ & \\
Education & 8 \\
Less than year 12 or equivalent & 4 \\
Year 12 or equivalent & 11 \\
Certificate & 3 \\
Advanced Diploma/Diploma & 3 \\
Bachelor's Degree & 3 \\
Grad Dip/Grad Cert & 2 \\
Master's Degree & \\
Ethnicity & 31 \\
Australian & 1 \\
Torres Strait Islander/Aboriginal & 2 \\
Australian Aboriginal & \\
\hline
\end{tabular}




\begin{tabular}{ll}
\hline Variables & $\mathbf{n}=\mathbf{3 4}$ \\
\hline Employment Status & \\
Casual employment & 7 \\
Full-time employment & 9 \\
Home duties & 8 \\
Part-time employment & 9 \\
Unemployed & 1 \\
Marital Status & \\
Defacto & 4 \\
Divorced & 6 \\
Married & 17 \\
Single-never married & 7 \\
\hline
\end{tabular}

Table 2. Demographic information of children with type 1 diabetes.

\begin{tabular}{ll}
\hline Variables & $\boldsymbol{n}=\mathbf{3 5}$ \\
\hline Age & 2 \\
$2-4$ & 1 \\
$5-8$ & 12 \\
$9-12$ & 19 \\
$13-18$ & \\
Gender & 18 \\
Female & 17 \\
Male & \\
BMI & 1 \\
$11-15$ & 17 \\
$16-20$ & 9 \\
$21-25$ & 6 \\
$26-30$ & 2 \\
$>30$ & \\
HbA1C & 15 \\
$>9.0 \%$ & 7 \\
$8.6 \%$ - 9.0\% & 3 \\
$8.1 \%$ - 8.5\% & 5 \\
$7.6 \%$ - 8.0\% & \\
$6.5 \%$ - 7.5\% & 4 \\
$<6.5 \%$ & 1 \\
Current Treatment & \\
Insulin Pump (CSII) & 11 \\
Flexible Insulin Dosing (fMDI) & 10 \\
Multiple Daily Injections (MDI) & 14 \\
\hline
\end{tabular}

The item mean scores and standard deviations out of the PedsQL Diabetes Module 3.0 questionnaire are presented in Table 3 and the relationships between the variables are described in Table 4. There were no statistically significant differences in diabetic specific HRQoL between the groups as determined by a one-way ANOVA- diabetes $\{F(2,31)=$ $0.517, p=0.601\}$, treatment $\{F(2,31)=0.385, p=0.684\}$, worry $\{F(2,31)=0.076, p=0.927\}$, and communication $\{F$ $(2,31)=0.672, p=0.518\}$. A Tukey post hoc test revealed that there were no statistically significant differences between the treatment groups (see Table 3 ).

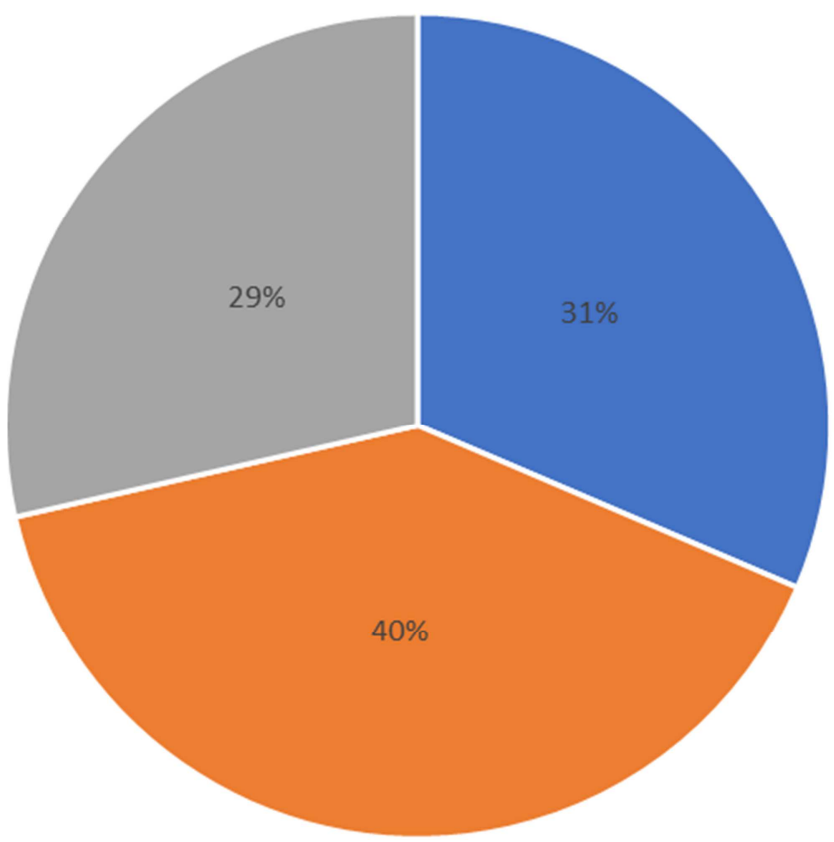

Figure 2. The pie chart showing the proportion of the children and adolescents being treated by CSII, MDI and FMDI. CSII- 31\%, MDI- $40 \%$ and $f M D I-29 \%$.

Table 3. Peds $Q L$ summary outcome.

\begin{tabular}{|c|c|c|c|c|c|c|c|c|c|c|c|}
\hline \multirow{3}{*}{ Statement } & & \multicolumn{10}{|c|}{ Age Group } \\
\hline & & \multicolumn{2}{|c|}{$2-4$ years } & \multicolumn{2}{|c|}{$5-7$ years } & \multicolumn{2}{|c|}{ 8-12 years } & \multicolumn{2}{|c|}{$\begin{array}{l}\text { 13-18 years } \\
\text { (completed by } \\
\text { parent) }\end{array}$} & \multicolumn{2}{|c|}{$\begin{array}{l}\text { 13-18 years } \\
\text { (completed by } \\
\text { self) }\end{array}$} \\
\hline & & n & M (SD) & $n$ & $M$ & n & M (SD) & $n$ & $M(S D)$ & $\mathbf{n}$ & M (SD) \\
\hline \multirow{11}{*}{$\begin{array}{l}\text { DIABETES } \\
\text { (problems with) }\end{array}$} & Feeling hungry & 2 & $25(1.41)$ & 1 & 75 & 12 & $42.5(0.87)$ & 14 & $37.5(0.85)$ & 5 & $60(1.14)$ \\
\hline & Feeling Thirsty & 2 & $37.5(0.71)$ & 1 & 75 & 12 & $42.5(0.75)$ & 14 & $52.5(1.0)$ & 5 & $75(0.71)$ \\
\hline & Having to go to the toilet too often & 2 & $50(1.41)$ & 1 & 100 & 12 & $65(0.79)$ & 14 & $70(1.15)$ & 5 & $85(0.55)$ \\
\hline & Having stomach aches & 2 & $87.5(0.71)$ & 1 & 100 & 12 & $67.5(0.78)$ & 14 & $70(1.03)$ & 5 & $75(1.41)$ \\
\hline & Having headaches & 2 & $87.5(0.71)$ & 1 & 50 & 12 & $65(1.08)$ & 14 & $67.5(0.83)$ & 5 & $80(0.84)$ \\
\hline & Going "low" or "hypo" & 2 & $62.5(0.71)$ & 1 & 100 & 12 & $45(1.03)$ & 14 & $47.5(0.47)$ & 5 & $55(1.10)$ \\
\hline & Feeling tired & 2 & $62.5(0.71)$ & 1 & 100 & 12 & $57.5(0.65)$ & 14 & $45(0.77)$ & 5 & $70(0.84)$ \\
\hline & Getting shaky & 2 & $87.5(0.71)$ & 1 & 100 & 12 & $67.5(0.97)$ & 14 & $62.5(0.85)$ & 5 & $80(0.84)$ \\
\hline & Getting sweaty & 2 & $62.5(0.71)$ & 1 & 100 & 12 & $72.5(0.9)$ & 14 & $70(0.66)$ & 5 & $90(0.89)$ \\
\hline & Having trouble sleeping at night & 2 & $50(1.41)$ & 1 & 75 & 12 & $70(1.11)$ & 14 & $62.5(1.02)$ & 5 & $90(0.55)$ \\
\hline & Getting grumpy or annoyed & 2 & $50(1.41)$ & 1 & 75 & 12 & $42.5(0.97)$ & 14 & $45(1.14)$ & 5 & $75(1.41)$ \\
\hline \multirow{3}{*}{$\begin{array}{l}\text { TREATMENT } \\
\text { (Problems with) }\end{array}$} & Injections/blood tests causing pain & 2 & $62.5(0.71)$ & 1 & 75 & 12 & $60(0.90)$ & 14 & $60(1.22)$ & 5 & $75(1.00)$ \\
\hline & $\begin{array}{l}\text { Getting embarrassed about having } \\
\text { diabetes }\end{array}$ & 2 & $87.5(0.71)$ & 1 & 100 & 12 & $67.5(1.15)$ & 14 & $70(1.35)$ & 5 & $65(0.89)$ \\
\hline & $\begin{array}{l}\text { Arguing with parent about diabetes } \\
\text { care }\end{array}$ & 2 & $75(0.0)$ & 1 & 100 & 12 & $52.5(1.31)$ & 14 & $60(1.4)$ & 5 & $80(1.10)$ \\
\hline
\end{tabular}




\begin{tabular}{|c|c|c|c|c|c|c|c|c|c|c|c|}
\hline \multirow{3}{*}{ Statement } & & \multicolumn{10}{|c|}{ Age Group } \\
\hline & & \multicolumn{2}{|c|}{$2-4$ years } & \multicolumn{2}{|c|}{$5-7$ years } & \multicolumn{2}{|c|}{ 8-12 years } & \multicolumn{2}{|c|}{$\begin{array}{l}13-18 \text { years } \\
\text { (completed by } \\
\text { parent) }\end{array}$} & \multicolumn{2}{|c|}{$\begin{array}{l}\text { 13-18 years } \\
\text { (completed by } \\
\text { self) }\end{array}$} \\
\hline & & $\mathbf{n}$ & M (SD) & $n$ & $M$ & $\mathbf{n}$ & M (SD) & $n$ & $M(S D)$ & $\mathbf{n}$ & M (SD) \\
\hline \multirow{8}{*}{ TREATMENT 2} & Sticking to diabetes routine & 2 & $50(1.10)$ & 1 & 100 & 12 & $60(0.90)$ & 14 & $45(1.33)$ & 5 & $75(0.71)$ \\
\hline & $\begin{array}{l}\text { It is hard for my child to do blood } \\
\text { glucose tests }\end{array}$ & 2 & $75(0.0)$ & 1 & 100 & 12 & $82.5(0.98)$ & 14 & $75(1.11)$ & 5 & $90(0.55)$ \\
\hline & $\begin{array}{l}\text { It is hard for my child to give } \\
\text { himself insulin injections }\end{array}$ & 2 & $67.5(2.1)$ & 1 & 0 & 12 & $67.5(1.42)$ & 14 & $80(0.97)$ & 5 & $80(0.84)$ \\
\hline & It is hard for my child to exercise & 2 & $87.5(0.71)$ & 1 & 100 & 12 & $85(0.51)$ & 14 & $62.5(1.29)$ & 5 & $80(1.10)$ \\
\hline & $\begin{array}{l}\text { It is hard for my child to follow a } \\
\text { healthy diet }\end{array}$ & 2 & $75(0.0)$ & 1 & 100 & 12 & $65(1.08)$ & 14 & $67.5(1.27)$ & 5 & $80(0.84)$ \\
\hline & $\begin{array}{l}\text { It is hard for my child to wear his } \\
\text { id bracelet/necklace or carry a card }\end{array}$ & 2 & $87.5(0.71)$ & 1 & 0 & 12 & $67.5(1.56)$ & 14 & $65(1.55)$ & 5 & $40(1.67)$ \\
\hline & $\begin{array}{l}\text { It is hard for my child to carry a } \\
\text { fast-acting carbohydrate }\end{array}$ & 2 & $75(0.0)$ & 1 & 100 & 12 & $82.5(0.78)$ & 14 & $62.5(1.02)$ & 5 & 75 (1.41) \\
\hline & $\begin{array}{l}\text { It is hard for my child to eat snacks } \\
\text { between meals when they should }\end{array}$ & 2 & $87.5(0.71)$ & 1 & 100 & 12 & $82.5(0.67)$ & 14 & $67.5(1.34)$ & 5 & $70(1.10)$ \\
\hline \multirow{3}{*}{$\begin{array}{l}\text { WORRY (problems } \\
\text { with) }\end{array}$} & $\begin{array}{l}\text { Worrying about "going low" or } \\
\text { "hypo" }\end{array}$ & 2 & $62.5(0.71)$ & 1 & 100 & 12 & $50(1.21)$ & 14 & $50(1.11)$ & 5 & 65 (1.52) \\
\hline & $\begin{array}{l}\text { Worrying about whether or not } \\
\text { medical treatments are working }\end{array}$ & 2 & $62.5(0.71)$ & 1 & 100 & 12 & $55(1.11)$ & 14 & $62.5(1.16)$ & 5 & $80(0.84)$ \\
\hline & $\begin{array}{l}\text { Worrying about long-term } \\
\text { problems of diabetes }\end{array}$ & 2 & $37.5(2.12)$ & 1 & 100 & 12 & 45 (1.64) & 14 & $52.5(1.33)$ & 5 & $60(0.89)$ \\
\hline \multirow{3}{*}{$\begin{array}{l}\text { COMMUNICATIO } \\
\mathrm{N} \text { (problems with) }\end{array}$} & $\begin{array}{l}\text { Telling the doctors and nurses how } \\
\text { he/she feels }\end{array}$ & 2 & $37.5(0.71)$ & 1 & 100 & 12 & $77.5(1.38)$ & 14 & $70(1.20)$ & 5 & $80(0.84)$ \\
\hline & $\begin{array}{l}\text { Asking the doctor or nurses } \\
\text { questions }\end{array}$ & 2 & $75(1.41)$ & 1 & 100 & 12 & $80(1.40)$ & 14 & $72.5(1.10)$ & 5 & $90(0.55)$ \\
\hline & $\begin{array}{l}\text { Explaining his/her illness to other } \\
\text { people }\end{array}$ & 2 & $75(1.41)$ & 1 & 100 & 12 & $77.5(1.24)$ & 14 & $67.5(1.07)$ & 5 & $70(1.10)$ \\
\hline
\end{tabular}

Table 4. Post-hoc comparisons for quality of life.

\begin{tabular}{lllll}
\hline Dependent Variable & \multicolumn{2}{l}{ Treatment } & Mean Difference & Sig. \\
\hline Diabetes & IP & MDI & 0.154 & 0.998 \\
& & FID & -0.290 & 0.677 \\
& MDI & IP & -0.154 & 0.998 \\
& & FID & -0.264 & 0.623 \\
Freatment & FID & IP & -0.250 & 0.677 \\
& & MDI & 0.264 & 0.623 \\
& IP & MDI & 0.018 & 1.00 \\
& & FID & -0.264 & 0.734 \\
Morry & MDI & IP & -0.018 & 1.00 \\
& & FID & -0.265 & 0.713 \\
& FID & IP & 0.264 & 0.734 \\
& & MDI & 0.265 & 0.713 \\
& IP & MDI & -0.062 & 0.977 \\
& & FID & 0.058 & 0.982 \\
& MDI & IP & 0.062 & 0.977 \\
& & FID & 0.120 & 0.921 \\
& \multirow{2}{*}{ FID } & IP & -0.058 & 0.982 \\
& & MDI & -0.120 & 0.921 \\
& IP & MDI & 0.110 & 0.956 \\
& & FID & -0.339 & 0.692 \\
& FIDI & IP & -0.110 & 0.956 \\
& & FID & -0.450 & 0.502 \\
& & IP & 0.339 & 0.502 \\
\hline \multirow{2}{*}{ Fommication } & & & 0.449 &
\end{tabular}

\section{Discussion}

Our study was conducted in a regional centre in Tasmania, which has the highest prevalence of T1D in children among all the Australian states, being 166 per 100,000 population and its demographic features were similar to the overall national trends as per the Australian Institute of Health and Welfare, 2013 report. (2) Like the national figure, T1D rates were similar for both males and females. Rates for children aged 10-14 were more than 10 times higher than for children aged $0-4$. Treatment regimen data also showed that nearly one-third of children in our study used CSII as opposed to $43 \%$ nationwide.

Diagnosis of diabetes is a life changing experience for the whole family unit. The management of diabetes is complicated, as treatment affects the everyday life of both children and their families. For the optimal care of children with T1D, it is important to highlight the importance of HRQoL as well as glycaemic control. HRQoL is an important factor which strongly influences the glycaemic control and psychosocial functioning. [13] In this study we identified no significant difference of HRQoL among the types of intensive insulin therapy. However, other influencing factors of HRQoL are worth reviewing in this regard. Types of diabetic complication, for example, exert variable impact on HRQoL, like the presence of nephropathy, but not retinopathy, reduced the subjective HRQoL in patients with T1D. [14] Tighter glycaemic control is unequivocally associated with better HRQoL. [15] While managing the children with T1D, various protective factors are important to recognise and should be promoted whenever possible for better HRQoL. Greater child protective factors are associated with better diabetes resilience, including higher child HRQoL and lower parental depression and stress. Generally, a positive correlation is found between the child's age whereas a negative correlation is found between the number of children in the family and the HRQoL of the child 
and parents. [16]. Child's gender also plays an important role. To identify the main factors influencing the diabetic specific HRQoL (D-HRQoL), the TEENs study which was an international, cross-sectional study of youth between 8 to 25 years of age, with T1D, found across all age groups, females reported significantly lower D-HRQoL than did males. Better glycaemic control, advanced methods used to measure food intake, more frequent daily blood glucose monitoring and more days of physical activity were all associated with better HRQoL. [17] Other studies have also found that girls seem to need extra support. [18].

There are number of comparative studies available to look at the HRQoL in children treated with either MDI or CSII. In Denmark, for example, parents reported children and adolescents on CSII for more than one year have less diabetesrelated symptoms and worry, less problems in communicating diabetes, and better generic functioning compared with those on MDI. For less than one year, there was, however, no differences identified, apart from the less treatment barriers in the MDI. [19] Adding CGM to CSII significantly improves metabolic control but interestingly had no positive impact on HRQoL in children. [20] Physical activity has been curiously investigated as a potential influencing factor for D-HRQoL. Higher Vo2max and the CSII therapy were significant predictors of the better HRQoL, however, other clinical and anthropometric variables did not have any effect in a study conducted to identify the factors influencing the D-HRQoL. The good cardiorespiratory fitness (expressed by Vo2max) has been found to have clinical and HRQoL benefits for paediatric patients with T1D. [21].

Comorbidities are also an important factor in the management of T1D. Previous studies results show that living with an additional disease, such as psychiatric illnesses, has an impact on the HRQoL. [22] There were nearly $26.6 \%$ children and adolescents with T1D with comorbid psychiatric illness as identified in previous studies. The most common diagnoses were: anxiety $(\mathrm{N}=32 ; 15.5 \%)$ and mood disorders $(\mathrm{N}=8 ; 3.9 \%)$. One-third of the patients $(31.9 \%)$ met the criteria for at least one psychiatric diagnosis in a lifetime period. The presence of psychiatric disorders was related with elevated $\mathrm{HbA1c}(8.6 \%$ vs. $7.6 \%)$ and lowered HRQoL in the general PedsQL. In the diabetes-specific PedsQL children with psychiatric disorders revealed more symptoms of diabetes, treatment barriers and lower adherence than children without psychiatric disorders. [23] Comorbidities also play an important role in parental satisfaction. HRQoL and glycaemic control in youth with T1D and coeliac disease vs T1D only were compared. Youth with T1D and celiac disease who do not adhere to the gluten-free diet have lower HRQoL and worse glycaemic control. [24].

Insulin type and timing in relation to meal time is also important factor for HRQoL. Although pre-prandial administration of insulin aspart is generally preferable, one study found that in children and adolescents, postprandial administration of insulin aspart is a safe and effective alternative.(25) When diabetes is diagnosed, multiple injections become a part of daily life. It is estimated that $22 \%$ of general population has needle phobia, often shared by several family members. Also, in phobic children multiple injections therapy can induce discomfort and pain. Effectivity of indwelling catheter on metabolic control and HRQoL in children and adolescents with T1D and in their mothers suggested HbA1c significantly improved 3 months after the application of the device $(\mathrm{p}=0.002)$. This improvement was preserved up to 1 year, with improvement of clinically significant stress from $53 \%$ to $3 \%$ of children and adolescents, suggesting the use of i-Port Advance improves the quality of life of caregivers and children, as well as the metabolic control. [26] Another useful component aiming to improve the treatment outcome, telephone calls from a paediatric diabetes educator to children who have T1D were regularly attempted to identify its impact on HbAlc level, hospital admissions, diabetes knowledge, compliance, and psychological well-being. This had shown there was no significant difference between the treatment and control groups either before or after the intervention. Scheduled bimonthly phone support does not improve the HbAlc level, admission rates, diabetes knowledge, psychological function, or self-management but is perceived by patients as helpful. [27] For young children with T1D, CSII therapy is comparable to MDI therapy with regard to glucose control but is associated with higher treatment satisfaction and improved HRQoL. [28] Our study added that the type of intensive therapy did not make any statistically significant difference on the HRQoL.

\section{Limitations}

\section{Small sample size}

2. Modes of associated glucose estimation were not looked at in this study. Different children on various glucose monitoring systems like finger-prick glucometer, flash glucometer or CGM may have the variable influencing effect on HRQoL.

\section{Conclusion}

Although, the impact of T1D on the HRQoL in children and adolescents is higher than the children without T1D, it appears to be independent of the types of three intensive insulin therapy generally used- CSII, MDI and fMDI, suggesting type of insulin therapy may not be the major influencing factor for children' quality of life as revealed in this first of its kind study. A further study with higher number of participants and the additional impact of various glucose monitoring systems on the HRQoL is highly recommended, which may influence the decision of right therapy suitable for the entire family

\section{References}

[1] Kalyva E, Malakonaki E. Health - related quality of life (HRQoL) of children with type 1 diabetes mellitus (T1DM): self and parental perceptions. diabetes [Internet]. 2011; 12 (1):34-40. 
[2] Aihw. Prevalence of Type I diabetes among children aged 015 in Australia. 2013;(24):1-24.

[3] Coghill D, Hodgkins P. Health-related quality of life of children with attention-deficit/hyperactivity disorder versus children with diabetes and healthy controls. European Child and Adolescent Psychiatry. 2015.

[4] Nathan DM. The diabetes control and complications trial/epidemiology of diabetes interventions and complications study at 30 years: Overview. Diabetes Care. 2014; 37 (1):9-16.

[5] Szypowska A, Schwandt A, Svensson J, Shalitin S, CardonaHernandez R, Forsander G, et al. Insulin pump therapy in children with type 1 diabetes: analysis of data from the SWEET registry. Pediatr Diabetes. 2016; 17:38-45.

[6] Li YLA. Quality of Life in Parents of Children with Type 1 Diabetes Receiving Insulin Treatment. [Internet]. Quality of Life in Parents of Children with Type 1 Diabetes Receiving Insulin Treatment. 2014.

[7] Group DS. Training in flexible, intensive insulin management to enable dietary freedom in people with Type 1 diabetes: dose adjustment for normal eating (DAFNE) randomized controlled trial. Diabet Med. 2003; 20 Suppl 3:4-5.

[8] Alemzadeh R, Palma-Sisto P, Parton E, Totka J, Kirby M. Beneficial effects of flexible insulin therapy in children and adolescents with type 1 diabetes mellitus. Acta Diabetol. 2003; 40 (3):137-42.

[9] MURILLO M, BEL J, CORRIPIO R, CARRERAS G, HERRERO X, MENGIBAR J-M, et al. Health-related quality of life (HRQOL) and its associated factors in children with Type 1 Diabetes Mellitus (T1DM). BMC Pediatr [Internet]. 2017; $17(1): 1-9$.

[10] Stahl A, Strassburger K, Lange K, Bachle C, Holl RW, Giani $\mathrm{G}$, et al. Health-related quality of life among German youths with early-onset and long-duration type 1 diabetes. Diabetes Care. 2012 Aug; 35 (8):1736-42.

[11] Wagner VM, Müller-Godeffroy E, Von Sengbusch S, Häger S, Thyen U. Age, metabolic control and type of insulin regime influences health-related quality of life in children and adolescents with type 1 diabetes mellitus. Eur J Pediatr. 2005; 164 (8):491-6.

[12] Varni JW, Burwinkle TM, Jacobs JR, Gottschalk M, Kaufman F, Jones KL. The PedsQL ${ }^{\mathrm{TM}}$ in Type 1 and Type 2 Diabetes. Diabetes Care. 2003; 26 (3):631-7.

[13] Peterson C, $\mathrm{A}^{\circ}$ kesson K, Hanberger L, Samuelsson U. Healthrelated quality of life of children with type 1 diabetes and the relation to metabolic control. Pediatr Diabetes [Internet]. 2015; 16:134.

[14] Ahola AJ, Saraheimo M, Forsblom C, Hietala K, Sintonen H, Groop P-H. Health-related quality of life in patients with type 1 diabetes--association with diabetic complications (the FinnDiane Study). Nephrol Dial Transplant. 2010; 25 (6):1903-8.

[15] Hesketh KD, Wake MA, Cameron FJ. Health-related quality of life and metabolic control in children with type 1 diabetes: a prospective cohort study. Diabetes Care. 2004; 27 (2):41520 .
[16] Özyazicioğlu N, Avdal ET, Sağlam H. A determination of the quality of life of children and adolescents with type 1 diabetes and their parents. Int J Nurs Sci. 2016.

[17] Anderson BJ, Laffel LM, Domenger C, Danne T, Phillip M, Mazza C, et al. Factors Associated With Diabetes- Specific Health-Related Quality of Life in Youth With Type 1 Diabetes: The Global TEENs Study. Diabetes Care [Internet]. 2017; 40 (8):1002-9.

[18] Hanberger L, Ludvigsson J, Nordfeldt S. Health-related quality of life in intensively treated young patients with type 1 diabetes. PediatrDiabetes [Internet]. 2009; 10 (1399-5448 (Electronic) LA-eng PT-Journal Article PT-Research Support, Non-U.S. Gov't SB-IM):374-81.

[19] Birkebaek NH, Kristensen LJ, Mose AH, Thastum M. Quality of life in Danish children and adolescents with type 1 diabetes treated with continuous subcutaneous insulin infusion or multiple daily injections. Diabetes Res Clin Pract. 2014 Dec; 106 (3):474-80.

[20] H. G, J. C, E. H, B. S. O, T. B, I. C, et al. The switch study: The impact of continuous glucose monitoring on quality of life and treatment satisfaction [Internet]. Vol. 15, Value in Health. 2012. p. A359.

[21] Lukacs A, Varga B, Kiss-Toth E, Soos A, Barkai L. Factors influencing the diabetes-specific health-related quality of life in children and adolescents with type 1 diabetes mellitus. J Child Health Care. 2014; 18 (3):253-60.

[22] Petersson C, Huus K, Samuelsson U, Hanberger L, Akesson K. Use of the national quality registry to monitor health-related quality of life of children with type 1 diabetes: a pilot study. J Child Health Care. 2015; 19 (1):30-42.

[23] Butwicka A, Fendler W, Zalepa A, Szadkowska A, Zawodniak-Szalapska M, Gmitrowicz A, et al. Psychiatric Disorders and Health Related Quality of Life in Children with Type 1 Diabetes Mellitus. Psychosomatics [Internet]. 2015; 57 (2):185-93.

[24] Pham-Short A, Donaghue KC, Ambler G, Garnett S, Craig ME. Quality of Life in Type 1 Diabetes and Celiac Disease: Role of the Gluten-Free Diet. J Pediatr. 2016 Dec; 179:131138.e1.

[25] Danne T, Aman J, Schober E, Deiss D, Jacobsen JL, Friberg $\mathrm{HH}$, et al. A comparison of postprandial and preprandial administration of insulin aspart in children and adolescents with type 1 diabetes. Diabetes Care [Internet]. 2003; 26 (8):2359-64.

[26] A. Z, P. V, S. C, A. T, E. C, A. C, et al. Injection pain and anxiety in children and adolescents with type 1 diabetes: Can an indwelling catheter (i-Port Advance) improve metabolic control and quality of life? [Internet]. Vol. 18, Diabetes Technology and Therapeutics. 2016. p. A123-4.

[27] Nunn E, King B, Smart C, Anderson D. A randomized controlled trial of telephone calls to young patients with poorly controlled type 1 diabetes. Pediatr Diabetes [Internet]. 2006; 7 (5):254-9.

[28] Opipari-arrigan L, Fredericks EM, Burkhart N, Dale L, Hodge M, Foster C. Continuous subcutaneous insulin infusion benefits quality of life in preschool-age children with type 1 diabetes mellitus. Pediatr Diabetes. 2007; 8 (6):377-83. 